\title{
THE CONTRIBUTION OF PARTICLES WASHED FROM ROOFTOPS TO CONTAMINANT LOADING TO URBAN STREAMS
}

Peter C. Van Metre and Barbara J. Mahler, U.S. Geological Survey, Austin, Texas

\begin{abstract}
Rooftops are both a source of and a pathway for contaminated runoff in urban environments. To investigate the importance of particle-associated contamination in rooftop runoff, particles washed from asphalt shingle and galvanized metal roofs at two distances from a major expressway were analyzed for major and trace elements and PAHs. Concentrations and yields from rooftops were compared between locations and roofing material types to evaluate rooftop sources and their potential contribution to stream loading. Concentrations of zinc, lead, pyrene, and chrysene on a mass per mass basis exceeded established sediment quality guidelines for probable toxicity to benthic biota. Yields of all contaminants investigated were greater from sites nearer to the expressway, although some concentrations were lower. Yields of particle-bound zinc, cadmium, and nickel were significantly greater from metal roofs, and yields of lead were significantly greater from asphalt shingle roofs.
\end{abstract}

\section{RÉSUMÉ}

Dans les environnements urbains, les toits sont à la fois une source et un chemin pour le ruissellement contaminé. Pour mieux comprendre l'importance de la contamination associée aux particules dans le ruissellement des toits, nous avons analysé les particules provenant de deux sortes de toits, à deux distances d'une autoroute, en termes d' éléments majeurs, mineurs et de HAPs. Les concentrations de zinc, plomb, pyrène et chrysène, associés aux particules, ont excédé les recommandations établiees pour la toxicité probable à la faune benthique. Pour tous les contaminants la masse superficielle spécifique à été plus importante pour les toits plus proches de l'autoroute, même dans les cas où les concentrations ont été moins importantes. La masse superficielle spécifique de zinc, cadmium et nickel associés aux particules, étaient plus importante pour les toits en métal que pour les toits en asbestos shingle, tandis que pour le plomb c'était plutôt l'inverse.

\section{INTRODUCTION}

Particle-bound contaminants are widespread in the urban environment, leading to the impairment of water quality in many urban streams and lakes. Rooftops can play an important role in the pathway that contaminants travel between a source (the atmosphere) and a receptor (an urban stream or lake) (Förster, 1999; Davis et al., 2001). In addition, roofs themselves can be a source of contamination through the leaching and disintegration of roofing materials. Most studies of contaminants in rooftop runoff have focused on the occurrence of trace elements in filtered or unfiltered aqueous samples of runoff with the objective of determining roof runoff toxicity. Only a few studies have considered the occurrence of PAHs in rooftop runoff (Daub et al., 1994; Steuer et al., 1997; Förster, 1999), and few investigators have focused on the contaminant fraction bound to particles.

In this study we focus on the trace element and $\mathrm{PAH}$ content of fine particles washed off of two types of roofs: galvanized metal and asphalt shingle. The study was designed to address two questions: (1) How do rooftop particle chemistry and contaminant yield vary with distance from a major expressway? and (2) what are the yields of trace elements and PAHs in particles from roofing materials? To answer these questions, we sampled particles washed from asphalt shingle and galvanized metal roofs with similar geometries, located at two distances from a major expressway in Austin, Texas, USA. The particles were isolated by filtration and analyzed for a suite of major and trace elements and organic compounds.

\section{EXPERIMENTAL METHODOLOGY}

\subsection{Rooftop Sampling}

The study was carried out at Camp Mabry, a retired U.S. Army fort in Austin, Texas. Camp Mabry is adjacent to the MoPac Expressway about $5 \mathrm{~km}$ northwest of the downtown Austin area (Figure 1). The buildings at Camp Mabry are symmetric, one-story, and shed-roofed, are about 90-m long by $15-\mathrm{m}$ wide, and have either asphalt shingle or galvanized metal roofs. The east and west ends of the buildings are 12 and $102 \mathrm{~m}$ from the paved shoulder of MoPac, respectively. The MoPac Expressway is a limited access, interstate-style roadway with six traffic lanes and a 2-track rail line down the middle. Traffic volume for the stretch of highway next to Camp Mabry for 1999 was 134,000 cars per day (CAMPO, 1999). The predominant wind direction in Austin is from the south-southeast and secondarily from the north-northeast, generally parallel to MoPac in the area of Camp Mabry (Figure 1).

Rooftop washoff was sampled from four of the buildings and from the adjacent shoulder of MoPac on three occasions following dry weather periods of between two weeks and one month. To compensate for any effect that orientation of the roof might have on deposition, each sample was a composite of water recovered from opposite-facing sections of roof of the same type at the same distance from the 
$2^{\text {nd }}$ International Symposium on Contaminated Sediments $2^{\text {ième }}$ Symposium International sur les Sédiments Contaminés

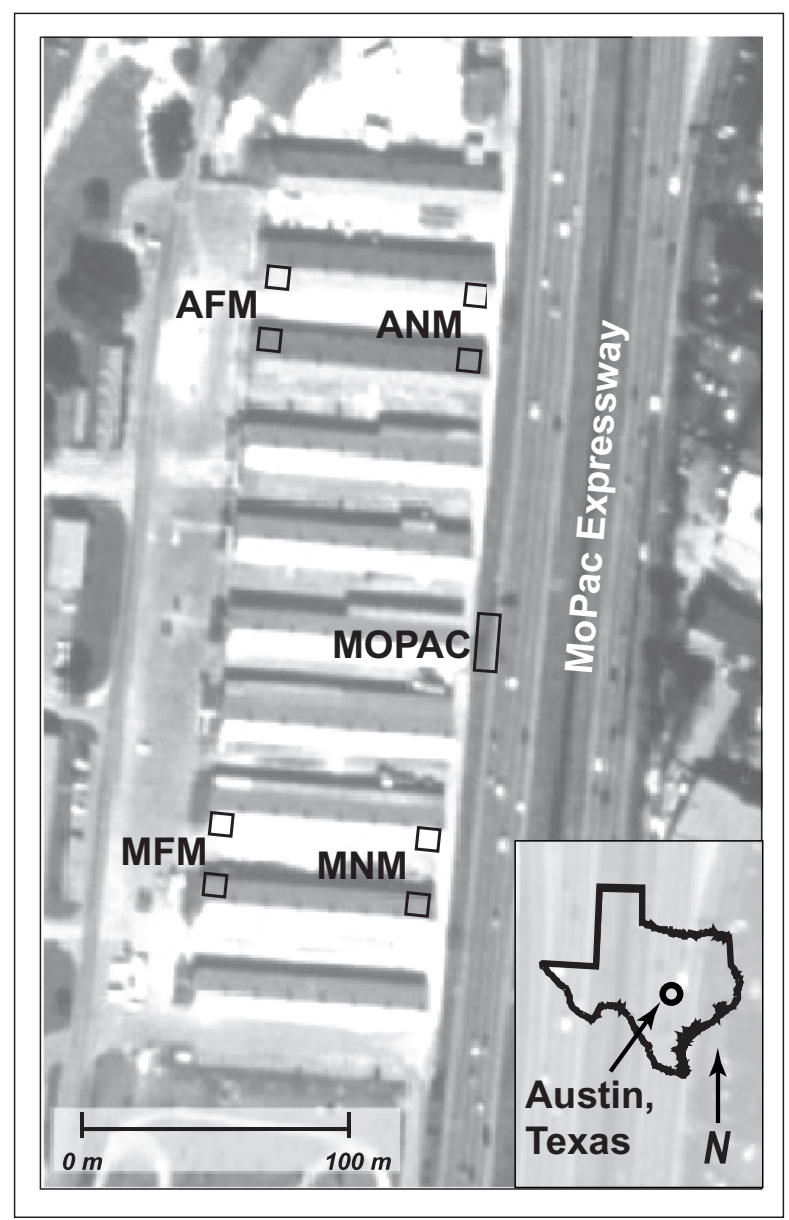

Figure 1. Location of sampling sites in Austin, Texas. The sites are: metal roofs nearest MoPac (MNM), metal roofs farthest from MoPac (MFM), asphalt shingle roofs nearest MoPac (ANM), asphalt shingle roofs farthest from MoPac (AFM), and the MoPac Expressway shoulder (MoPac).

expressway. The sites sampled were: metal roofs at the east end of buildings 37 and 38 (nearest MoPac) (MNM), metal roofs at the west end of buildings 37 and 38 (farthest from MoPac) (MFM), asphalt shingle roofs at the east end of buildings 31 and 32 (ANM), and asphalt shingle roofs at the west end of buildings 31 and 32 (AFM) (Figure 1). The roofing materials on all four buildings appeared to be at least several years old and showed moderate wear.

Sections of rooftop were sprayed with Austin city tap water. The runoff was collected in pre-cleaned PVC gutters installed at the base of an area of roof, passed through a $63-\mu \mathrm{m}$ nylon mesh, and collected in a $200-\mathrm{L}$ Teflon-bag lined barrel. Particles washed off of the MoPac expressway were pumped up at the end of the roadway strip, passed through a 63- $\mu \mathrm{m}$ nylon mesh, and collected in Nalgene carboys.
Physical Characterization / Caractérisation physique

\subsection{Sample processing and analytical procedures}

Sediment was isolated on site using inline filtration, following the methods of Mahler and Van Metre (2003). Samples for analysis of major and trace elements were freeze-dried and ground to a fine powder, then completely digested using a mixture of hydrochloric-nitric-perchloric-hydrofluoric acids and analyzed by inductively-coupled plasma/mass spectrometry (ICP/MS) or by cold vapor AAS at a USGS laboratory in Denver, Colorado (Arbogast, 1996). Samples for analysis of PAHs were chilled and sent to the USGS National Water Quality Laboratory for analysis. The glassfiber filters were extracted and analyzed using a variation of the procedures of Furlong et al. (1996). Total PAH as presented here is the sum of 18 parent PAHs and their alkylated homologues. Samples of unfiltered water were collected during filtration for analysis of suspendedsediment concentration (Guy, 1969).

\section{RESULTS AND DISCUSSON}

Particle-associated contamination from rooftop runoff was evaluated through examination of concentrations as indicators of potential toxicity and of yields as indicators of source strength. Statistical differences between groups of samples were tested using the sign test (Helsel and Hirsch, 1992). Trace element and PAH concentrations and yields were compared between the two roof types and between samples collected nearer to and farther from the MoPac expressway. In each case, six pairs of samples (three sampling events with two matched pairs of roof type or location for each event) were available for testing. Five of six samples larger than their matched pair resulted in a $p$-value of 0.11 and six of six in a p-value of 0.016 . We chose to reject the null hypothesis of no difference between the groups at $p \leq 0.11$. For those groups that were determined to be significantly different a coefficient of difference $\left(C_{d}\right)$ was computed, expressed as the ratio of the median difference between the pairs to the median of all samples; the larger the $C_{d}$, the larger the difference between the groups. $\mathrm{A} \mathrm{C}_{\mathrm{d}}$ exceeding 0.5 was considered large.

\subsection{Concentrations of particle-associated contaminants}

Concentrations of trace elements were compared between the two types of roofs (metal versus asphalt: MNM and MFM versus ANM and AFM) and between the locations of the roofs (near MoPac versus far from MoPac: MNM and ANM versus MFM and AFM) (Figure 2 and Table 1). With the exceptions of lead and mercury, concentrations of all trace elements considered were significantly higher in samples from the metal roofs than those from the asphalt shingle roofs. The differences were most pronounced for zinc and cadmium. Lead and mercury were significantly higher in samples from the asphalt shingle roofs, with relatively high $C_{d}$ values ( 0.95 and 0.88 , respectively). Concentrations of cadmium, chromium, and copper were higher in samples closer to the expressway, and concentrations of arsenic and nickel were higher in samples 

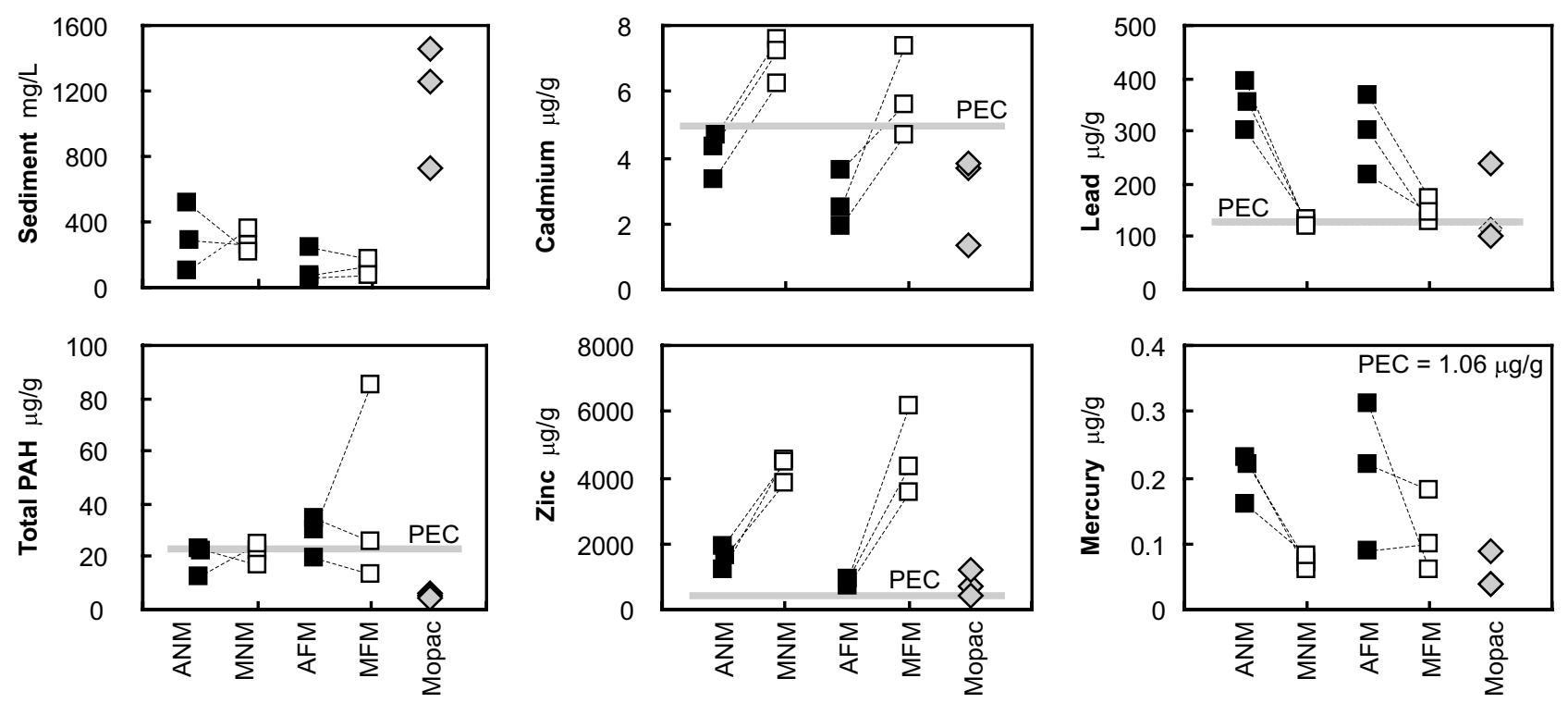

Figure 2. Concentrations of selected constituents in rooftop and MoPac shoulder particles. Sites are shown on figure 1. Symbols are: asphalt roofs $(\boldsymbol{\square})$; metal roofs $(\square)$; MoPac shoulder $(\diamond)$. Paired samples linked by dashed lines are asphalt versus metal roofs at similar distance from MoPac. PEC is the probable effects concentration sediment quality guideline (MacDonald et al., 2000).

farther from the expressway, but the differences were not as pronounced as some of those between roof types (Table 1). Mercury, lead, and zinc did not show any spatial differences in concentration.

No differences in concentrations of PAHs were observed between the two types of roofs (Table 1), negating our working hypothesis that deterioration of asphalt shingle roofs contributes PAHs to the environment. Concentrations of 7 of the 10 PAHs statistically tested (not shown) and total $\mathrm{PAH}$ were higher in the samples collected farther from the expressway, with $C_{d}$ values from 0.31 to 0.42 . This too was unexpected, because a second working hypothesis was that $\mathrm{PAH}$ concentrations would be higher closer to the expressway.

While many investigators have demonstrated that concentrations of contaminants in rooftop runoff exceed drinking-water guidelines or have documented the toxicity of rooftop runoff to aquatic organisms (e.g., Yaziz et al., 1989; Good, 1993; Thomas and Greene, 1993), the results described here indicate that particle-bound contaminants washed from rooftops may contribute to sediment toxicity in receiving water bodies. Particles in some rooftop washoff

Table 1. Statistically significant differences between sample pairs and coefficients of difference ${ }^{1}$ for paired values.

\begin{tabular}{|c|c|c|c|c|c|c|c|c|c|c|}
\hline \multirow{2}{*}{\multicolumn{11}{|c|}{$\frac{\text { Comparison }}{\text { Concentrations }}$}} \\
\hline & & & & & & & & & & \\
\hline $\begin{array}{l}C_{d} \text { asphalt versus metal } \\
\left(C_{d} \text { negative if metal }>\text { asphalt }\right)\end{array}$ & nd & -0.15 & -0.63 & -0.03 & -0.12 & 0.88 & -0.14 & 0.95 & -1.14 & nd \\
\hline $\begin{array}{l}C_{d} \text { near versus far from MoPac } \\
\left.\text { ( } C_{d} \text { negative if far }>\text { near }\right)\end{array}$ & 0.86 & -0.16 & 0.32 & 0.08 & 0.29 & $n d$ & -0.10 & $n d$ & $n d$ & -0.31 \\
\hline
\end{tabular}

Yields

$\mathrm{C}_{\mathrm{d}}$ asphalt versus metal

$\left(\mathrm{C}_{\mathrm{d}}\right.$ negative if metal $>$ asphalt $) \quad n d \quad n d-0.56 \quad$ nd $\quad$ nd $\quad$ nd $\quad \begin{array}{lllllll}-0.12 & 0.79 & -1.01 & \text { nd }\end{array}$

$C_{d}$ near versus far from MoPac

$\left(C_{d}\right.$ negative if far $>$ near $)$

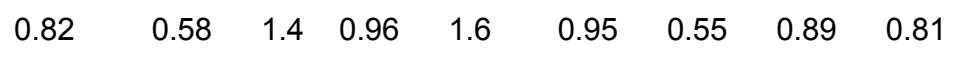

0.47

$n d=$ difference not statistically significant.

${ }^{1}$ coefficient of difference $\left(C_{d}\right)$ is the ratio of the median difference between the pairs to the median of all samples. 

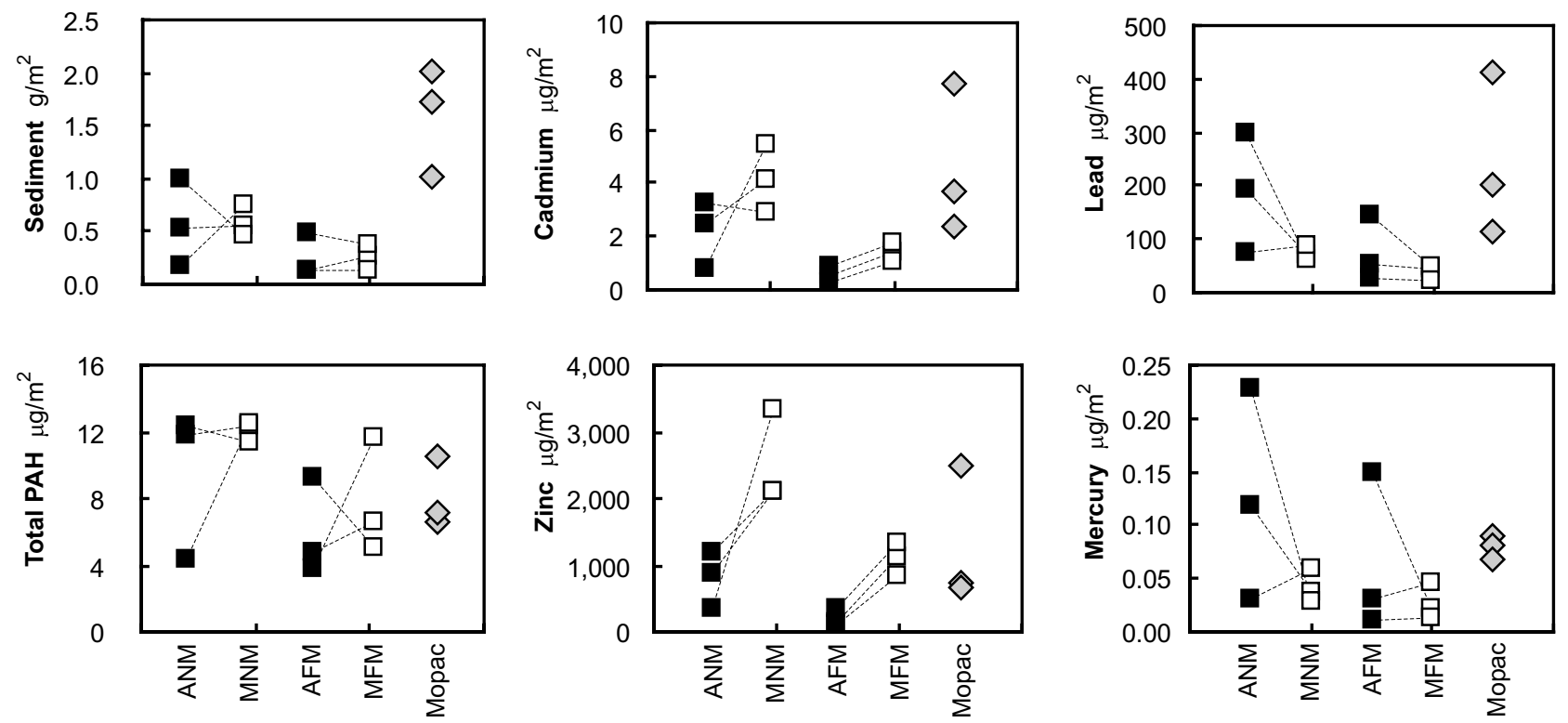

Figure 3. Yields of selected constituents in rooftop and MoPac shoulder samples. Graphs follow same general layout as figure 2.

samples contained trace elements and PAHs at concentrations that could pose a threat to benthic biota, based on comparison to published consensus-based sediment quality guidelines (SQGs) (MacDonald et al., 2000). In particular, concentrations of particle-bound zinc, lead, cadmium, pyrene, chrysene and total PAH in rooftop washoff particles exceeded the Probable Effects Concentrations (PECs; MacDonald et al., 2000) in numerous samples (Figure 2).

\subsection{Yields of particle-associated contaminants}

Trace element and PAH yields were compared between the two roof types and between samples collected nearer to and farther from the MoPac expressway (Table 1). Contaminant yield is directly proportional to particle yield because contaminant yield is computed as the product of contaminant concentration and total particle yield. NearMoPac total particle yields were significantly larger than far from MoPac particle yields, with a $C_{d}$ of 0.82 .

Roofing material significantly affected the yields of several trace elements (Figure 3). Of the eight elements considered, three (cadmium, nickel, and zinc) had greater yields from metal roofs and the differences for cadmium and zinc were large $\left(C_{d}\right.$ values of 0.56 and 1.01, respectively). One element, lead, had a greater yield from asphalt shingle roofs $\left(\mathrm{C}_{d}\right.$ of 0.79$)$. Although mercury had significantly higher concentrations in particles from asphalt roofs and much greater yields in some samples from asphalt shingle roofs, there was no significant difference in yields. Computed yields for asphalt shingle roofs for the four trace elements reported by Quek and Förster (1993) (cadmium, copper, lead, and zinc) were similar in magnitude to those they reported for tar felt and asbestos roofs; but the yield of zinc for metal roofs computed from this study was almost two orders of magnitude less than reported by Quek and Förster.

All eight elements considered had significantly higher yields from the near-MoPac rooftops than the far-MoPac rooftops, with $C_{d}$ values ranging from 0.55 for nickel to 1.55 for copper. Even arsenic and nickel, elements that had higher concentrations in the far-MoPac samples, had greater yields from the near-MoPac sites (Table 1).

Yields from the MoPac expressway exceeded those from all rooftops for arsenic, chromium, copper, and nickel. They generally exceeded those from asphalt roofs for cadmium and zinc, and exceeded those from metal roofs for mercury and lead. Yields for copper, lead, and zinc were more than an order of magnitude greater than those reported by Barrett et al. (1995) for annual loads from MoPac calculated on a $\mathrm{mg} \mathrm{m}^{-2} \mathrm{~mm}^{-1}$ basis. This is probably because the Barrett et al. study computed annual loads normalized to total annual precipitation whereas this study analyzed only the first flush-had a greater volume of water been sprayed on the roofs, the load per millimeter of "rain" would have decreased.

Little difference in yields of $\mathrm{PAH}$ was seen between the roof types, but PAH yields from the sites nearer to MoPac consistently exceeded those from sites farther from MoPac (Table 1). Only the three lightest of the individual PAHs had greater yields from metal roofs, and the differences were not large. All 10 individual $\mathrm{PAHs}$ and total $\mathrm{PAH}$ had greater yields from the near-MoPac sites, with $C_{d}$ values ranging from 0.33 to 0.5 for all PAHs except naphthalene, which had a $C_{d}$ of 1.3 . 
$2^{\text {nd }}$ International Symposium on Contaminated Sediments $2^{\text {ième }}$ Symposium International sur les Sédiments Contaminés

The apparent contradiction between concentrations and yields is explained by a combination of greater contaminant loading and sediment dilution near the roadway. We suggest that traffic along the MoPac Expressway is a source of trace elements and PAHs to the atmosphere, resulting in greater contaminant loading near the expressway. We also suggest that the road shoulder adjacent to the expressway is a source of uncontaminated particles that dilute contaminant concentrations-that erosion of soils next to the expressway combined with air turbulence caused by traffic results in lower concentrations of contaminants on the MoPac shoulder and in the near-MoPac samples, even though contaminant yields are higher. Inspection of the $C_{d}$ values indicates that this effect is more important for the trace elements than for the PAHs, suggesting either that particles containing PAHs travel farther before deposition than those containing trace elements, or that regional fallout sources of PAHs are more important compared to vehicle emissions. The effect of proximity to the expressway was greatest for copper and cadmium, two metals with a welldefined vehicular source (copper is used in brake pads; cadmium is found in tires) (Harrison and Johnston, 1985).

The results described above-higher contaminant concentrations farther from the roadway-are seemingly in contradiction with other studies that have reported an inverse relation between contaminant concentration in soils and distance from roadway (Yassoglou et al., 1987; Sutherland and Tolosa, 2001). This, however, is because these studies involved collecting samples directly from the ground surface. On the ground, contaminants are already mixed with and diluted by soils, so that under those sampling conditions concentration is a surrogate for yield.

The asphalt shingle roofing material sampled for this study was found to be a source of lead and possibly mercury. Lead concentrations and yields were significantly higher in particles washed from asphalt shingle roofs than in those washed from metal roofs. Asphalt shingle roofs may also be a source of mercury. Concentrations of mercury associated with particles washed from asphalt shingle roofs were significantly higher than those associated with particles washed from metal roofs, but yields of mercury were not. In three of the six paired sets of samples, mercury yields from asphalt shingle roofs were greater than those from metal roofs, and in the other three the opposite was found. However, in those cases where mercury yields from asphalt shingle roofs exceeded those from metal roofs, the difference was much greater (3-8 times greater) than when the yields from metal roofs exceeded those from asphalt shingle (1-2 times greater). Regional atmospheric fallout is generally thought to be the major source of mercury in the environment (Swain et al., 1992) but does not explain the elevated concentrations of mercury often seen in urban sediments, thus the possibility that asphalt shingle roofs may be a source of mercury to the urban environment is intriguing and warrants further investigation.
Physical Characterization / Caractérisation physique

\section{SUMMARY AND CONCLUSIONS}

The effects of roofing type and proximity to a major expressway on concentrations and yields of particle-bound contaminants washed from roofs were evaluated. The particles have relatively high levels of some contaminants as indicated by comparison to SQGs. Concentrations of particle-bound zinc and lead exceeded SQGs predicting toxicity for benthic organisms in the majority of samples from both types of roofs, and cadmium exceeded the guidelines for five of six samples from metal roofs. Concentrations of total PAH exceeded the guidelines in half of the samples, and two PAHs, chrysene and pyrene, exceeded the guidelines in 75 percent or more of the samples.

For particle-bound contaminants, yields were more useful than concentrations in determining the effect of roadway proximity and rooftop type on loading. Yields of all PAHs and trace elements analyzed were higher for samples collected close to a major expressway than those for samples collected farther away. The differences were greater for the trace elements than for the PAHs, and were greatest for copper and cadmium. The results indicated that the metal roofing material sampled was a source of particlebound zinc, cadmium, and nickel, and that the asphalt shingles sampled were a source of particle-bound lead and possibly mercury. There was no evidence that asphalt shingle roofs were a source of PAHs.

\section{ACKNOWLEDGMENTS}

This research was supported by the USGS and the City of Austin, Texas. We thank the State of Texas, Adjutant General's Department, for permission to conduct sampling at Camp Mabry. Any use of trade, product, or firm names is for descriptive purposes only and does not constitute endorsement by the USGS.

\section{REFERENCES}

Arbogast, B.F. (Ed.) 1996. Analytical methods manual for the Mineral Resource Surveys Program, U.S. Geological Survey. U.S. Geological Survey Open-File Report 96-0525.

Bannerman, R.T., Owens, D.W., Dodds, R.B., and Hornewer, N.J. 1993. Sources of pollutants in Wisconsin stormwater. Water Science Technology 28(3-5), 241259.

Barrett, M.E., Malina, J.F., Charbeneau, R.J., and Ward, G.H. 1995. Characterization of highway runoff in the Austin, Texas area. CRWR 263, Center for Research in Water Resources, University of Texas at Austin, Austin, Texas. 
$2^{\text {nd }}$ International Symposium on Contaminated Sediments

$2^{\text {ième }}$ Symposium International sur les Sédiments Contaminés

Capital Area Metropolitan Planning Organization (CAMPO). 1999. 1999 State Roadway Traffic Volume Report. http://www.ci.austin.tx.us/campo/1999_state_roadway_ traffic_volume_report.pdf, accessed January 21, 2002.

Daub, J., Förster, J., Herrmann, R., Robien, A., and Striebel, T. 1994. Chemodynamics of trace pollutants during snowmelt on roof and street surfaces. Water Science Technology 30(1), 73-85.

Davis, A.P., Shokouhian, M., and Ni, S. 2001. Loading estimates of lead, copper, cadmium, and zinc in urban runoff from specific sources. Chemosphere 44(5), 997-1009.

Förster, J. 1999. Variability of roof runoff quality. Water Science Technology 39(5), 137-144.

Furlong, E.T., Vaught, D.G., Merten, L.M., Foreman, W.T., and Gates, P.M. 1996. Methods of analysis by the U.S. Geological Survey National Water Quality LaboratoryDetermination of semivolatile organic compounds in bottom sediment by solvent extraction, gel permeation chromatographic fractionation, and capillary-column chromatography/mass spectrometry. U.S. Geological Survey Open-File Report 95-719.

Good, J.C. 1993. Roof runoff as a diffuse source of metals and aquatic toxicity in storm water. Water Science Technology 28(3-5), 317-321.

Guy, H.P. 1969. Laboratory theory and methods for sediment analysis. U.S. Geological Survey Techniques of Water-Resources Investigations, book 5, chap. C1, 58 p.

Harrison, R.M., and Johnston, W.R. 1985. Deposition fluxes of lead, cadmium, copper and polynuclear aromatic hydrocarbons $(\mathrm{PAH})$ on the verges of a major highway. The Science of the Total Environment, Vol. 46, pp. 121-135.

Helsel, D.R., and Hirsch, R.M. 1992. Studies in environmental science 49-Statistical methods in water resources. Elsevier, Amsterdam.

MacDonald, D.D., Ingersoll, C.G., and Berger, T.A. 2000. Development and evaluation of consensus-based sediment quality guidelines for freshwater ecosystems. Archives of Environmental Contamination and Toxicology, Vol. 39, pp. 20-31.

Mahler, B.J., and Van Metre, P.C. 2003. A simplified approach for monitoring hydrophobic organic contaminants associated with suspended sedimentmethodology and applications. Archives of Environmental Contamination and Toxicology, Vol. 44, No. 3, pp. 288-297.

National Atmospheric Deposition Program. 2000. National Atmospheric Deposition Program 1998 wet depostion. NADP Data Report 2000-01, 15 p.
Physical Characterization / Caractérisation physique

Quek, U., and Förster, J. 1993. Trace metals in roof runoff. Water, Air, and Soil Pollution, Vol. 68, pp. 373-389.

Steuer, J., Selbig, W., Hornewer, N., and Prey, J. 1997. Sources of contamination in an urban basin in Marquette, Michigan and an analysis of concentrations, loads, and data quality. U.S. Geological Survey WaterResources Investigations Report 97-4242, 25 p.

Sutherland, R.A., and Tolosa, C.A. 2001. Variation in total and extractable elements with distance from roads in an urban watershed Honolulu, Hawaii. Water, Air, and Soil Pollution 127(1-4), 315-338.

Swain, E.B., Engstrom, D.R., Brigham, M.E., Henning, T.A., and Brezonik, P.L. 1992. Increasing rates of atmospheric mercury deposition in Midcontinental North America. Science 257(5071), 784-787.

Thomas, P.R., and Greene, G.R. 1993. Rainwater quality from different roof catchments. Water Science Technology 28(3-5), 291-299.

Yassoglou, N., Kosmas, C., Asimakopoulos, J., and Kallianou, C. 1987. Heavy metal contamination of roadside soils in the Greater Athens area. Environmental Pollution 47(4), 293-304.

Yaziz, M.I., Gunting, H., Sapri, N., and Ghazali, A.W. 1989. Variations in rainwater quality from roof catchments. Water Research 23(6), 761-765. 